\title{
Small-scale structures in neutrals and charged aerosol particles as observed during the ECOMA/MASS rocket campaign
}

\author{
B. Strelnikov, M. Rapp, I. Strelnikova, N. Engler, and R. Latteck \\ Leibniz Institute of Atmospheric Physics, Schloss-Str. 6, 18225 Kühlungsborn, Germany \\ Received: 4 November 2008 - Revised: 9 February 2009 - Accepted: 18 February 2009 - Published: 1 April 2009
}

\begin{abstract}
We present results of in situ measurements of neutral temperature during the ECOMA/MASS rocket campaign. We present and compare results of turbulence measurements conducted simultaneously by both in situ and doppler radar techniques. We show that the derived values of the turbulence energy dissipation rates are similar on average. We also find a region with a near adiabatic lapse rate with turbulence detected at the upper and lower edge. We note that it is consistent with expectation for a KelvinHelmholtz instability.

We also present an estimate of the Schmidt numbers, $S c$, for the charged aerosols that utilizes in situ measured smallscale density fluctuations of charged aerosols and both in situ and radar turbulence measurements. The derived Schmidt numbers fall within the range between 100 and 4500 . This result agrees with previous estimates based on multi-frequency observations of PMSE (Rapp et al., 2008) and also with estimates of microphysical parameters presented in the companion paper by Rapp et al. (2009).
\end{abstract}

Keywords. Atmospheric composition and structure (Aerosols and particles; Pressure, density, and temperature) - Meteorology and atmospheric dynamics (Turbulence)

\section{Introduction}

With the invention of suitable in situ techniques heavy meteoric smoke particles (MSP) in the mesosphere/lower thermosphere (MLT) region have recently been in the focus of several experimental studies (Havnes et al., 1996; Gelinas et al., 1998; Lynch et al., 2005; Rapp et al., 2005; Strelnikova et al., 2009). It is believed that these particles play a key role in MLT phenomena like polar mesosphere summer echoes

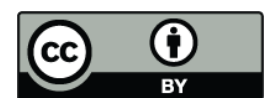

Correspondence to: B. Strelnikov (strelnikov@iap-kborn.de)
(PMSE) and noctilucent clouds (NLC). Under the conditions of the extremely cold summer polar mesopause these particles may act as nuclei for building large ice particles and, therefore, better knowledge on them is important for understanding the microphysics of these phenomena (e.g. Rapp and Thomas, 2006).

MSPs and ice particles are surrounded by the ionospheric plasma and gain a charge because of electron and ion capture processes. As initially proposed by Kelley et al. (1987) and later extended by Cho et al. (1992) and Rapp and Lübken (2004), charged aerosols should ultimately reduce the diffusivity of free electrons. In turbulence theory, this reduced diffusivity can be expressed in terms of high Schmidt numbers $S c=v / D$, a dimensionless number defined as the ratio of momentum diffusivity (viscosity) and mass (molecular) diffusivity. The first in situ measurements of $S c$ at PMSE heights by Lübken et al. (1994) and Lübken et al. (1998) utilized small-scale electron density and neutral density measurements and resulted in values between $\sim 6$ and 500 .

In August 2007 the joint European-American ECOMA/MASS sounding rocket campaign took place at the North-Norwegian Andøya Rocket Range $\left(69^{\circ} \mathrm{N}\right.$, see Rapp et al., 2009; Robertson et al., 2009, for details). The European part ECOMA stands for "Existence and Charge state Of meteoric smoke particles in the Middle Atmosphere" and is a sounding rocket program lead by the Leibniz-Institute of Atmospheric Physics (IAP) in Germany and the Norwegian Defense Research Establishment (FFI) with contributions from Sweden, Austria and the US. The main scientific objective of this program is studying MSPs in the middle atmosphere and their relation to mesospheric ice clouds. The first results of this program from an initial rocket flight in September 2006 are presented in Rapp and Strelnikova (2009) and Strelnikova et al. (2009), respectively.

In this paper we present results of the in situ measurements of small-scale structures in neutral air and charged aerosols

Published by Copernicus Publications on behalf of the European Geosciences Union. 
(ice particles) during the ECOMA/MASS rocket campaign. These measurements allow us to derive Schmidt numbers for the charged aerosols.

\section{Instrumentation}

The instrumentation of the ECOMA payload is described in detail in Strelnikova et al. (2009). As further described in detail in Rapp et al. (2009), the ECOMA sounding rocket campaign was supported by numerous ground-based observations. Here we briefly describe the instruments which were the main data sources for this paper.

\subsection{Rocket-borne instruments}

The payload instrumentation was similar to that described in Strelnikova et al. (2009). The main instrument, the ECOMA particle detector, is mounted on the front deck of the payload, and is designed to measure aerosol properties. A detailed description of the ECOMA instrument is presented in Rapp and Strelnikova (2009). In short, the ECOMA particle detector is a Faraday cup with two shielding grids biased at $\pm 6.2 \mathrm{~V}$, similar to the one first used by Havnes et al. (1996). Heavy aerosols pass through the biased grids and, if they carry a charge, produce a current which can be measured by a sensitive electrometer. Measurements of this current are analyzed in this article. Note, that neutral particles cannot be measured by this method. Also, because of aerodynamical effects, this method only allows to measure particles with radii larger than $\sim 2 \mathrm{~nm}$ (Horanyi et al., 1999; Rapp et al., 2005; Hedin et al., 2007).

In the rear, the payload was equipped with the CONE (=COmbined measurements of Neutrals and Electrons) instrument (see Giebeler et al., 1993). Basically, the CONE sensor is a spherical ionization gauge for the measurement of neutral density and is surrounded by a negatively biased grid (to shield the gauge from ambient electrons) and a positively biased spherical grid which is connected to a sensitive electrometer to measure electrons. The measurements of both neutrals and electrons are made at very high spatial resolution and high precision (i.e., altitude resolution $\approx 10 \mathrm{~cm}$; precision better than $0.1 \%$ ). Hence these measurements allow for the detection of small scale fluctuations in both species that arise due to processes like neutral air turbulence (Lübken et al., 2002) or plasma instability processes (Strelnikov et al., 2009). In addition, the height profile of neutral number densities can be integrated assuming hydrostatic equilibrium to yield a temperature profile at $\sim 200 \mathrm{~m}$ altitude resolution and an accuracy of $\sim 3 \mathrm{~K}$ (Rapp et al., 2001, 2002). The electron current measured by the outermost grid of the CONE sensor can also be converted to absolute electron number densities by normalizing it to the absolute (but spatially coarse) electron number densities derived from the radio wave propagation experiment (Friedrich et al., 2009).

\subsection{Ground-based instruments}

The ALWIN MST radar (Latteck et al., 1999) operating at $53.5 \mathrm{MHz}$ is located close to the rocket launch site at the Andøya Rocket Range. The radar is operated continuously throughout the whole year to study the dynamics and structure of the troposphere/lower stratosphere and Polar Mesosphere Summer Echoes (PMSE). PMSE observed by ALWIN with high temporal and spatial resolution were used as rocket launch criteria throughout the ECOMA/MASS campaign. During the rockets flights radar measurements of the PMSE power, radial velocity, and spectral width were obtained with a time resolution of $14 \mathrm{~s}$ and a height resolution of $50 \mathrm{~m}$.

\section{Data}

In situ measurements preformed during the ECOMA flight provided simultaneous and high-resolution measurements of neutral temperature, turbulence, density of neutral air and heavy charged particles. In this work we also use turbulence energy dissipation rates derived from the ALWIN radar measurements.

\subsection{Temperature}

In Fig. 1 we present the temperature profile derived from the CONE measurements. We see a well defined mesopause around $85 \mathrm{~km}$ height with temperatures lower than $120 \mathrm{~K}$. Comparing this profile with the frost point temperature (Fig. 1, dotted line) derived using the water vapor saturation pressure formula from Marti and Mauersberger (1993) and assuming a water mixing ratio $4.5 \mathrm{ppmv}$, which is a typical value for the NLC season at $69^{\circ} \mathrm{N}$ (Seele and Hartogh, 1999), we see that the air was supersaturated at altitudes between $\sim 80$ and $87 \mathrm{~km}$. As shown in Rapp et al. (2009) the PMSE heights observed during the ECOMA rocket launch fall within these altitudes.

The dashed line in Fig. 1 shows the dry adiabatic lapse rate. We see that in the height region between $\sim 79.5$ and $83.5 \mathrm{~km}$ the measured temperature profile exhibits a near adiabatic to superadiabatic lapse rate, that might be an indication of strong and persistent turbulent mixing at those heights.

\subsection{Turbulence}

The CONE turbulence measurements are based on the spectral model method introduced by Lübken et al. (1994) and extended by Strelnikov et al. (2003). First, we derive relative density fluctuations (residuals) by extracting a reference profile. The reference profile is usually derived from a moving average of the measured time series over the rocket spin period $(\sim 5 \mathrm{~Hz})$. Then the Fourier or global wavelet spectra of these residuals are subsequently fitted by a theoretical model 


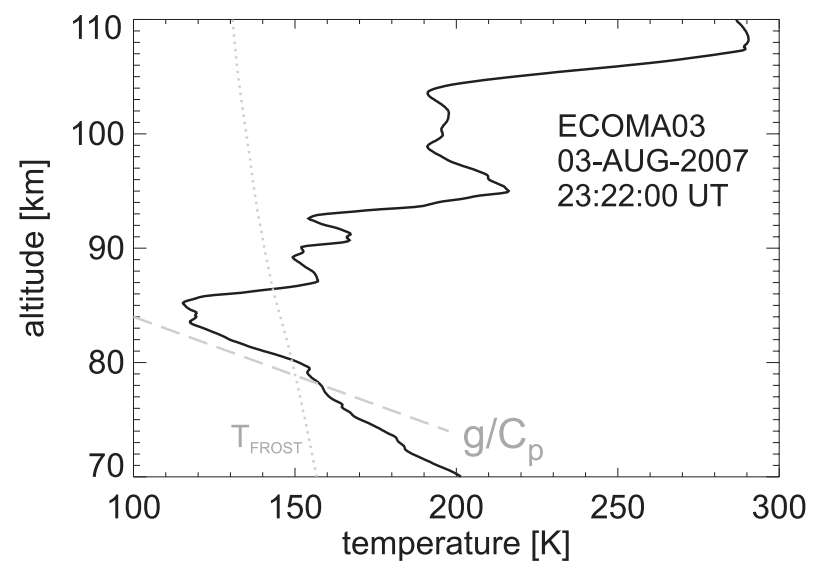

Fig. 1. Temperature measurements by CONE during ECOMA/MASS rocket campaign. The doted line shows frost point temperature derived using water vapor mixing ratio $4.5 \mathrm{ppmv}$. The dashed line shows the dry adiabatic lapse rate $\left(g / c_{p}\right)$.

of Heisenberg (1948) or Tatarskii (1971) yielding the energy dissipation rate, $\varepsilon$.

The results of the turbulence measurements during ECOMA flight are shown in Fig. 2. Two reference profiles shown by dotted and dashed lines are the minimum and the mean $\varepsilon$-values, respectively, representing turbulence climatology for polar summer MLT (see Strelnikov et al., 2003, for more details). In Fig. 2 we see two major regions of turbulence activity, one between $\sim 79$ and $86 \mathrm{~km}$ and the other between $\sim 89$ and $96 \mathrm{~km}$ height. For the upper turbulence region our analysis yielded a continuous profile of the energy dissipation rates with values ranging from weak $(\sim 10 \mathrm{~mW} / \mathrm{kg})$ to very strong $(\sim 2000 \mathrm{~mW} / \mathrm{kg})$ turbulence for those heights. In contrast, the lower turbulence region split into several turbulence layers revealing values of the energy dissipation rate which are on average more typical for those heights in summer season at $69^{\circ} \mathrm{N}$. It is interesting to note that at heights between $\sim 79.5$ and $83 \mathrm{~km}$, where the temperature measurements reveal a near-adiabatic to super-adiabatic lapse rate, a thin layer of turbulence activity was detected. Note that if turbulent mixing persist for some time then the neutral density fluctuations (used here as tracer) will adiabatically be washed out and our technique will not detect such structures. The actual temperature gradient is, however, not perfectly adiabatic everywhere so that the CONE sensor detects some structures at those heights (see also a similar observation and discussion in Lehmacher and Lübken, 1995).

As shown by Rapp et al. (2009) during the rocket launch the ALWIN radar observed a decaying PMSE event. From the sufficiently strong radar echoes it is possible to derive energy dissipation rates as described by Engler et al. (2005). Basically, that technique goes back to Hocking (1983) who applied a correction for beam and shear broadening based on the background wind field measurements, applied to the measured signal.

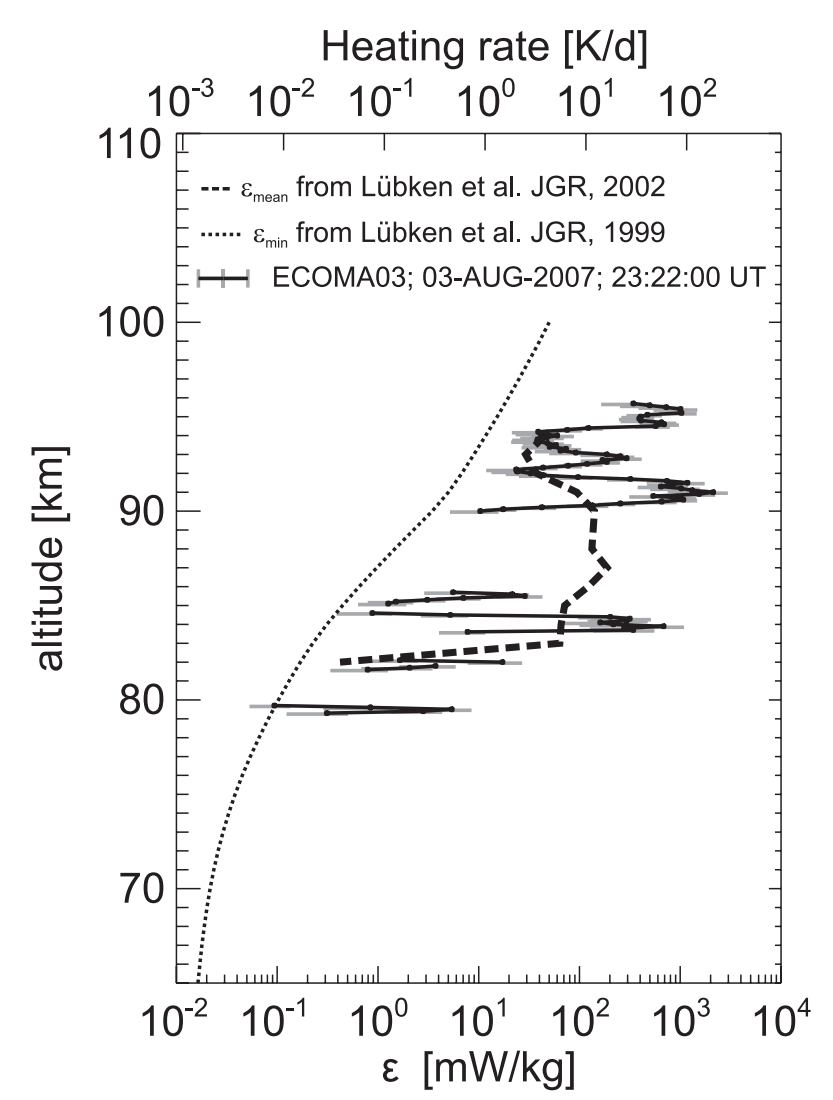

Fig. 2. In situ turbulence measurements during ECOMA flight. The dotted and dashed lines are the minimum and the mean $\varepsilon$-values, respectively, representing turbulence climatology for polar summer MLT.

Figure 3 shows energy dissipation rates derived from the radar measurements by the vertical $\left(0^{\circ}\right)$ and $7^{\circ} \mathrm{NW}$-tilted beam. The $\varepsilon$-values derived from the ALWIN radar around the ECOMA launch time are close to the mean value measured in situ in the region between 79 and $86 \mathrm{~km}$ and are equal to $16 \mathrm{~mW} / \mathrm{kg}$ on average. Similar to the in situ measurements, the backscattered power also shows two primary regions of structuring, one between $\sim 82$ and $84 \mathrm{~km}$ and the other between $\sim 86$ and $89 \mathrm{~km}$ height (see also Fig. 5 below). However, around the rocket launch time the power in the lower region is relatively weak so that it was not possible to derive energy dissipation rates at those heights with a sufficient reliability. As discussed in Rapp et al. (2009), where also the power of the radar echo is shown, the strength of the PMSE was drastically changing during the ECOMA/MASS salvo. Also the derived $\varepsilon$-values vary from $\sim 10$ to $\sim 40 \mathrm{~mW} / \mathrm{kg}$ during that time (Fig. 3 ).

Note that the ascending part of the rocket trajectory lies close to the ALWIN's $7^{\circ} \mathrm{NW}$-tilted beam whereas the descending part, that is when the CONE measurements were done, is $\sim 50 \mathrm{~km}$ away. Also the radar observations are representative of an average activity over a spatial region of about 

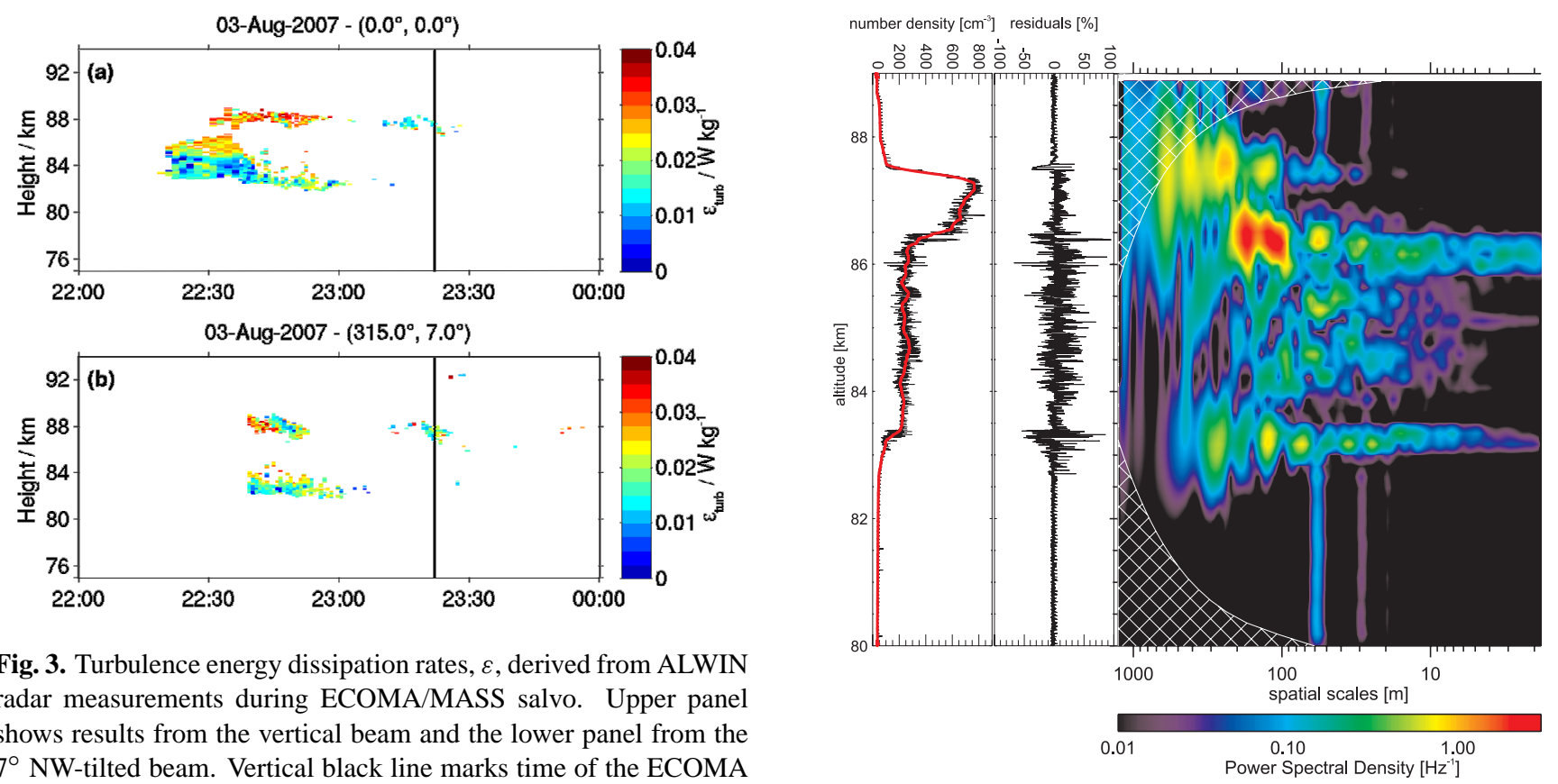

Fig. 3. Turbulence energy dissipation rates, $\varepsilon$, derived from ALWIN radar measurements during ECOMA/MASS salvo. Upper panel shows results from the vertical beam and the lower panel from the $7^{\circ} \mathrm{NW}$-tilted beam. Vertical black line marks time of the ECOMA launch at 23:22:00 UT.

$10 \mathrm{~km}$ in diameter at $85 \mathrm{~km}$ height whereas the CONE measurements can be considered as a point measurement.

The $7^{\circ} \mathrm{NW}$-tilted beam was pointing towards the rocket trajectory and probed the region through which the rocket passed during the upleg. That was the reason why we choose to use the data from the $7^{\circ}$ beam for further analysis. Also, comparing the vertical $\left(0^{\circ}\right)$ and the $7^{\circ}$ beam (see below, Fig. 5) we see that the lower layer of PMSE shifts up towards the rocket pass direction. The difference seen in the radar echoes from these two beams indicates that the observed structures were considerably inhomogeneous. This is also supported by the other in situ measurements by Rapp et al. (2009) and Megner et al. (2009) that observed a considerably different morphology of the ice layers during the upleg and downleg.

\subsection{Small-scale signatures in the particle measurements}

The measurements conducted with the ECOMA instrument are described in detail in Rapp et al. (2009). Among other things, the classical Faraday cup data channel of the ECOMA detector gives a current which is proportional to the number density of charged particles (DC-channel measurements, see Rapp and Strelnikova, 2009, for more details). Those measurements were done with a sufficiently high altitude resolution making it possible to perform a spectral analysis similar to that one described in Sect. 3.2 for the neutral density fluctuations. In the leftmost panel of Fig. 4 we show the ECOMA DC-channel (black line) and the reference profile (red line) that was determined to derive the relative fluctuations of the particle charge density (residuals). The resul-

Fig. 4. In situ charged aerosol density measurements during ECOMA flight (ECOMA DC-channel). Left panel: particle density (black) and reference profile (red) used to derive residuals. Middle panel: relative density fluctuations of charged particles (residuals). Right panel: wavelet power spectrum of the residuals (derived using Morlet-12 wavelet function).

tant residuals are shown in the middle panel of Fig. 4. The right panel of Fig. 4 shows the wavelet power spectrum of the charged particle residuals derived using a Morlet- 12 wavelet function. This figure shows that the charged particles were highly structured around $83 \mathrm{~km}$ and between 84 and $86.5 \mathrm{~km}$ height. The gap in small-scale structures between 83.5 and $84 \mathrm{~km}$ height is close to the altitudes where an adiabatic temperature gradient was measured in situ and, therefore (taking into account the distance between the turbulence- and particle probe measurements), can be explained either by the absence of turbulence or, as mentioned above, by persistent active turbulence that washed out the structures also in the charged aerosols.

Similar to Strelnikov et al. (2009), we now compare the charged particle density fluctuations with the ALWIN radar echo observed around the time of the in situ observations in order to check if the observed enhancement of spectral power in the dust data at altitudes between 83 and $88 \mathrm{~km}$ is indeed in situ evidence of PMSE (Fig. 5). According to Røyrvik and Smith (1984), the power $P$ observed by radar is directly proportional to the power spectral density (PSD) of the absolute electron number density fluctuations $\left(\Delta N_{e}\right)$ at the radar Bragg scale $\lambda_{\text {Bragg }}$ (i.e., the radar half wavelength): $P \propto \operatorname{PSD}\left(\Delta N_{e}, k\right)$, where $k=2 \pi / \lambda_{\text {Bragg }}$ is the wavenumber corresponding to the radar Bragg scale, which is $2.8 \mathrm{~m}$ for the ALWIN radar. However, high resolution 
measurements of the electron number density that could be used to determine $\operatorname{PSD}\left(\Delta N_{e}, k\right)$ are not available because the electron probe of the CONE instrument failed. However, it was shown by Rapp and Lübken (2003) and Lie-Svendsen et al. (2003) that fluctuations of electrons, positive ions, and charged aerosol particles that constitute the plasma at PMSE altitudes are coupled through multipolar diffusion processes. Hence, $\operatorname{PSD}\left(\Delta N_{e}, k\right)$ and $\operatorname{PSD}\left(\Delta N_{\text {ice }}, k\right)$ are proportional to each other (see Rapp et al., 2003, Fig. 5). Thus, we may compare the radar power with the corresponding particle density fluctuations shown in the spectrogram of Fig. 4. We note however, that this comparison is certainly only qualitative since the radio refractive index is given by the electron density and not by the particle charge density. Fluctuations of the particle density are indeed proportional to fluctuations of the electron density and, hence, the radio refractive index, but the proportionality factor is not precisely known (Rapp et al., 2003).

In the left panel of Fig. 5 we show the radar power from the vertical beam $\left(0^{\circ}\right.$, grey) and the $7^{\circ} \mathrm{NW}$-tilted beam (black) measured close to the rocket launch time. In the right panel of Fig. 5 we show the profile of the $\operatorname{PSD}\left(\Delta N_{\text {ice }}, 2.8 \mathrm{~m}\right)$ in dB (black) derived as a slice of the spectrogram from Fig. 4 at $2.8 \mathrm{~m}$. In the right panel of Fig. 5 we also show absolute electron density profile (grey) measured by the radio wave propagation technique and discussed in Friedrich et al. (2009). It is seen that the heights of the upper and the lower edge of the PMSE signature in the in situ measured charged particle fluctuations are similar to those observed by the radar. However, in contrast to the radar observations, the in situ data also show significant fluctuations inside the entire height region between 83 and $88 \mathrm{~km}$, that is between the PMSE layers observed by the ALWIN radar. There is, however, no contradiction between those in situ and radar data. As it is seen from the measurements (Fig. 5, right panel, grey profile), there was a "bite-out" in the electron densities observed in situ during the ECOMA flight (see Friedrich et al., 2009; Rapp et al., 2009, for details). As shown by Rapp et al. (2002a), there is lower electron density threshold for PMSE observations that is readily explained in terms of the standard theory of the scattering of the VHF radio waves. These authors found that at least a few hundreds electrons $/ \mathrm{cm}^{3}$ are required for a detectable PMSE. Hence, in our case there were too few electrons between $\sim 84$ and $\sim 86 \mathrm{~km}$ to lead to detectable radar backscatter.

It is interesting to note that the residual structuring in the charged particle density data is strongest at the top and the bottom of the entire region, that is inside the PMSE layers.

As for the case of the neutral density fluctuations, one can also fit a theoretical model to the spectra shown in Fig. 4. Following Lübken et al. (1994) who first derived Schmidt numbers from the high resolution in situ measurements of plasma (electron) density fluctuations, we fitted the model of Driscoll and Kennedy (1985) to the relative density fluctuations of the charged particle density.

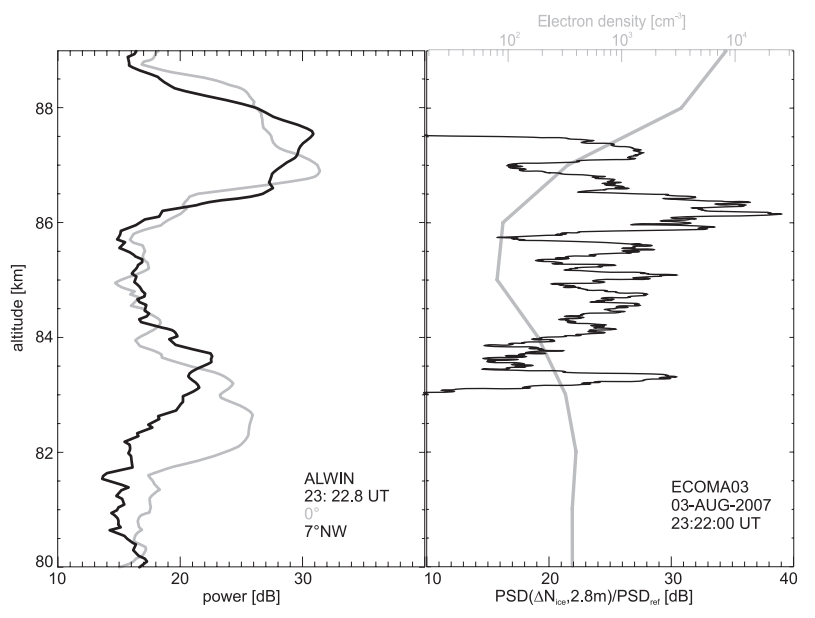

Fig. 5. Comparison of radar power and charged aerosol density fluctuations. Left panel: ALWIN radar power from vertical $\left(0^{\circ}\right.$, grey) and $7^{\circ} \mathrm{NW}$-tilted beam (black) observed near ECOMA launch time. Right panel: charged aerosol density fluctuations at ALWIN's Bragg scale $(2.8 \mathrm{~m})$ in $\mathrm{dB}$ (black) and absolute electron density profile (grey) measured by the radio wave propagation technique from Friedrich et al. (2009).

This procedure requires independently derived turbulence energy dissipation rates for the same volume where the plasma (charged particles in our case) fluctuations were observed. As described above, however, the CONE turbulence measurements are only available from the downleg, whereas the shown charged particle data were measured during the upleg. This leads to an uncertainty because the turbulent structures are most probably not as homogenous to reveal the same strength over $\sim 50 \mathrm{~km}$ extent. We have, however, also the radar turbulence measurements from the $7^{\circ} \mathrm{NW}$-radar beam, i.e., from the volume through which the ECOMA rocket passed. That means that we may also use the $\varepsilon$-values derived from the ALWIN measurements.

Taking into account that the radar averages over the relatively large volume, compared to the in situ measurements, we took the average $\varepsilon$-value which is $16 \mathrm{~mW} / \mathrm{kg}$ for the entire altitude range between $\sim 83$ and $89 \mathrm{~km}$.

Figure 6 shows an example of the residuals (upper panel), its 2-D spectrum (lower panel, thin oscillating line), and the best fit of the model by Driscoll and Kennedy (1985) (lower panel, bold line). The fit results in a Schmidt number $S c=541$. By changing the $\varepsilon$-value from the lowest $(1 \mathrm{~mW} / \mathrm{kg})$ to the highest $(1000 \mathrm{~mW} / \mathrm{kg})$ derived by the in situ technique we find that the $S c$-value changes from $\sim 917$ to $\sim 500$. This represents the uncertainty in the derivation of the Schmidt number presented here.

Thus, we fitted all the spectra shown in Fig. 4 in colour in the altitude range between 83 and $87 \mathrm{~km}$. The resultant Schmidt numbers are presented in Fig. 7 where the results shown by the thin black line utilize the ALWIN radar $\varepsilon$-measurements and the $S c$-values shown by the bold grey line were derived using in situ $\varepsilon$-measurements (Fig. 2). 

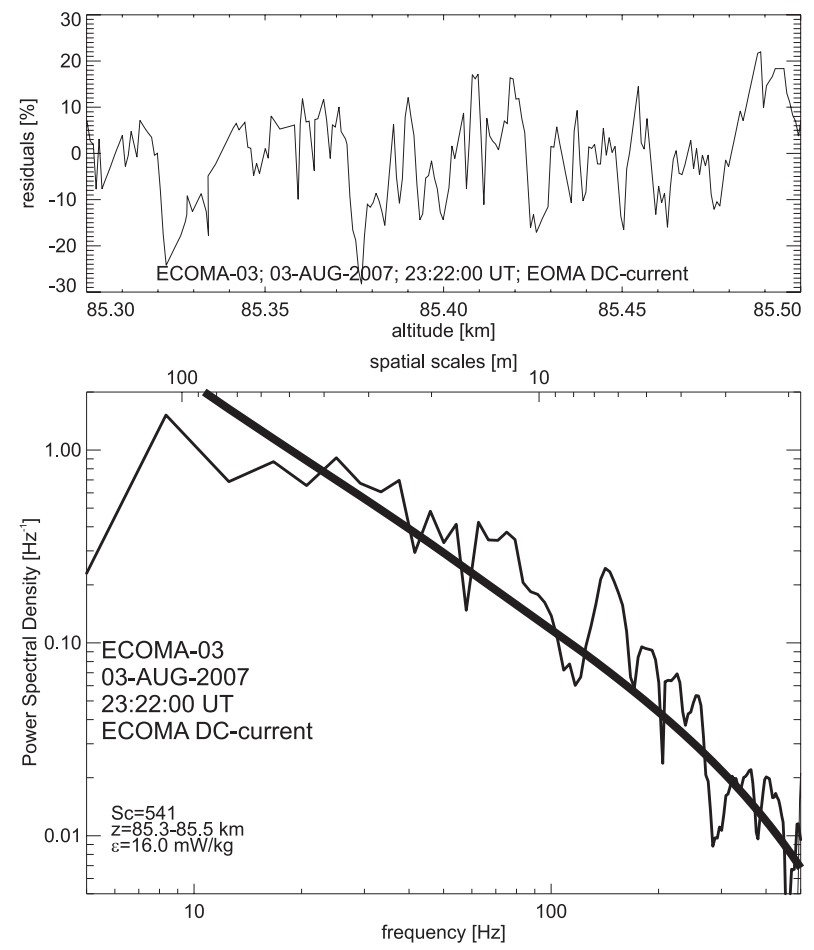

Fig. 6. Upper panel: relative density fluctuations (residuals) of the charged particle density measured in situ between 85.3 and $85.5 \mathrm{~km}$ height. Lower panel: Power spectral density of the residuals (thin line) and the best fit of the model by Driscoll and Kennedy (1985). The energy dissipation rate $\varepsilon=16 \mathrm{~mW} / \mathrm{kg}$ was taken from radar measurements. The derived Schmidt number $S c=541$.

We see that almost all the derived Schmidt numbers fall within the range from 100 to 2000 with only a few exceptions. Importantly, the small changes of the energy dissipation rate from one case to the other do not change the general range of Schmidt numbers derived from our measurements. Hence, the derived range of values, i.e., between 100 and 2000 , can be considered a robust result of our analysis.

\section{Discussion}

The mesopause temperature that was measured on the downleg reveals two local minima: above and below $\sim 84 \mathrm{~km}$. The other in situ downleg data by the photometer and ECOMA detector measured a relatively thin ice layer which only coincides with the upper local mesopause minimum (see Megner et al., 2009; Rapp et al., 2009). This ice layer also coincides with a relatively weak turbulence layer with $\varepsilon$-values ranging from 10 to $30 \mathrm{~mW} / \mathrm{kg}$.

Further below we observed turbulence layers and an adiabatic temperature gradient. We note that we observe turbulence above and below the altitudes with a near adiabatic lapse rate. This is somewhat reminiscent of the case of a Kelvin-Helmholtz billow studied in Gibson-Wilde et al.

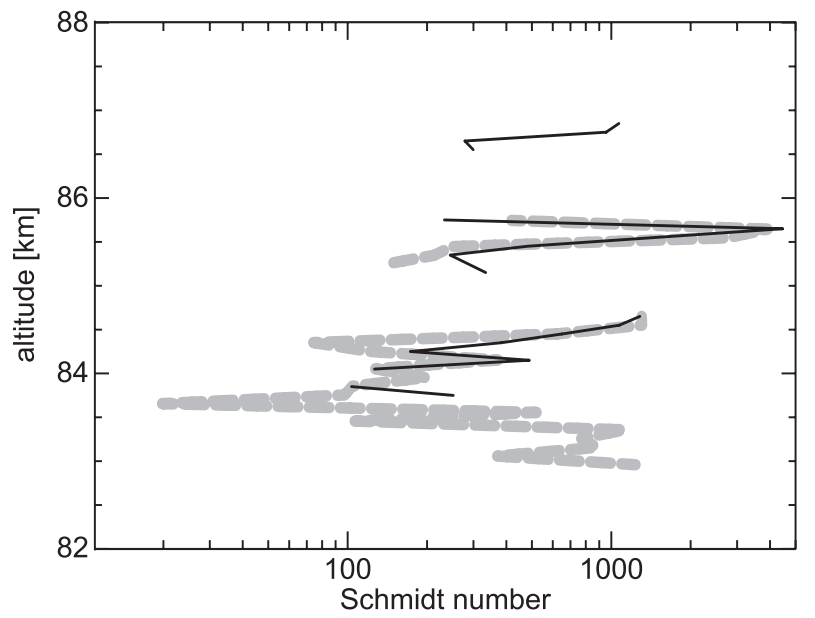

Fig. 7. Schmidt numbers derived from charged particle density and turbulence measurements during ECOMA flight. Thin black: using $\varepsilon$-values from ALWIN radar measurements. Bold grey: using in situ turbulence measurements.

(2000). They found that inside the billow strong mixing led to the disappearance of small-scale structures, and most pronounced irregularities were found at the upper and lower boundary of the billow.

Comparing the radar turbulence measurements with the in situ data (between 70 and $90 \mathrm{~km}$ heights) it is remarkable that they agree quite well if we only consider the upper turbulent layer from the in situ data. On average they show near the same turbulence strength.

Due to the $\sim 50 \mathrm{~km}$ horizontal separation of neutral air and charged particle measurements, we do not expect to see an exact overlap of the structures in those data. We utilized both the ALWIN radar and the in situ turbulence measurements to derive the Schmidt numbers for charged aerosols. Based on those measurements, we also varied the strength of turbulence in a large range of values which, however, did not lead to significant change in the derived Schmidt numbers. Moreover the both derived $S c$-profiles qualitatively agree (see Fig. 7).

We note that the very large $S c$-values of up to 4500 in our case derived for the heavy PMSE plasma constituent is in agreement with a previous independent $S c$-estimate by Rapp et al. (2008) derived from simultaneous radar measurements at different frequencies.

The large Schmidt numbers observed during the ECOMA flight are evidence of the low diffusivity of the detected particles which, according to Lübken et al. (1998), is related to the particle size by $S c=6.5 r^{2}$, where $r$ is the particle radius. Using this estimate we can compare results of our combined in situ and radar observations with those from Rapp et al. (2009) where the authors deduced an altitude-profile of the particles radii from a combination of the two data channels of the ECOMA particle detector, i.e., the Faraday cup 
measurements shown in Fig. 4, and the photoelectrons excited by the UV-photons of the xenon flashlamp of the detector, Rapp et al. (2009) derived radii of order $30 \mathrm{~nm}$ corresponding to Schmidt-numbers of $\sim 6000$. Taking into account the rather large uncertainty of the radii-estimates presented in Rapp et al. (2009), we consider this to be in good qualitative agreement with the estimates presented in Fig. 7.

\section{Conclusions}

We presented results of in situ temperature measurements and turbulence measurements conducted simultaneously by both in situ and doppler radar techniques during ECOMA/MASS rocket campaign. The derived values of the turbulence energy dissipation rates are similar on average.

We found a region with a near adiabatic lapse rate with turbulence detected at the upper and lower edge. We note that it is consistent with expectation for a Kelvin-Helmholtz instability.

We also showed estimated Schmidt numbers, $S c$, using high resolution measurements of charged particles along with our in situ and radar turbulence measurements. This resulted in large $S c$-values in the entire altitude range of the PMSE observation, i.e. Schmidt numbers between 100 and 4500 were observed. This is in line with previous estimates based on multi-frequency observations of PMSE (Rapp et al., 2008) and is also qualitatively consistent with the estimates of microphysical parameters presented in the companion paper by Rapp et al. (2009).

Acknowledgements. The ECOMA project is sponsored by the German Space Center under DLR-grant 50OE0301. The Norwegian part of the project was funded by the Norwegian Space Centre as project ECOMA 2006 and the Research Council of Norway, as project 170848. The Austrian contribution was funded under grant 18560 of the Austrian Science Foundation (FWF).

Topical Editor C. Jacobi thanks two anonymous referees for their help in evaluating this paper.

\section{References}

Cho, J. Y. N., Hall, T. M., and Kelley, M. C.: On the role of charged aerosols in polar mesosphere summer echoes, J. Geophys. Res., 97, 875-886, 1992.

Driscoll, R. J. and Kennedy, L. A.: A model for the spectrum of passive scalars in an isotropic turbulence field, Phys. Fluids, 28 , 72-80, 1985.

Engler, N., Latteck, R., Strelnikov, B., Singer, W., and Rapp, M.: Turbulent energy dissipation rates observed by Doppler MST Radar and by rocket-borne instruments during the MIDAS/MaCWAVE campaign 2002, Ann. Geophys., 23, 11471156, 2005,

http://www.ann-geophys.net/23/1147/2005/.

Friedrich, M., Torkar, K. M., Singer, W., Strelnikova, I., Rapp, M., and Robertson, S.: Signatures of mesospheric particles in iono- spheric data, Ann. Geophys., 27, 823-829, 2009,

http://www.ann-geophys.net/27/823/2009/.

Gelinas, L. J., Lynch, K. A., Kelley, M. C., Collins, S., Baker, S., Zhou, Q., and Friedman, J. S.: First observation of meteoric charged dust in the tropical mesosphere, Geophys. Res. Lett., 25(21), 4047-4050, doi:10.1029/1998GL900089, 1998.

Gibson-Wilde, D., Werne, J., Fritts, D., and Hill, R.: Direct numerical simulations of VHF radar measurements of turbulence in the mesosphere, Radio Sci., 35(3), 783-798, 2000.

Giebeler, J., Lübken, F.-J., and Nägele, M.: CONE - a new sensor for in-situ observations of neutral and plasma density fluctuations, Proceedings of the 11th ESA Symposium on European Rocket and Balloon Programmes and Related Research, Montreux, Switzerland (ESA SP), ESA-SP-355, 311-318, 1993.

Havnes, O., Trøim, J., Blix, T., Mortensen, W., Næsheim, L. I., Thrane, E., and Tønnesen, T.: First detection of charged dust particles in the Earth's mesosphere, J. Geophys. Res., 101, 10839-10847, 1996.

Hedin, J., Gumbel, J., and Rapp, M.: On the efficiency of rocketborne particle detection in the mesosphere, Atmos. Chem. Phys., 7, 3701-3711, 2007, http://www.atmos-chem-phys.net/7/3701/2007/.

Heisenberg, W.: Zur statistischen Theorie der Turbulenz, Z. Physik, 124, 628-657, 1948.

Hocking, W.: On the extraction of atmospheric turbulence parameters from radar backscatter doppler spectra - i. theory, J. Atmos. Terr. Phys., 45, 89-102, 1983

Horanyi, M., Gumbel, J., Witt, G., and Robertson, S.: Simulation of rocket-borne particle measurements in the mesosphere, Geophys. Res. Lett., 26, 1537-1540, 1999.

Kelley, M. C., Farley, D. T., and Roettger, J.: The effect of cluster ions on anomalous VHF backscatter from the summer polar mesosphere, Geophys. Res. Lett., 14, 1031-1034, 1987.

Latteck, R., Singer, W., and Bardey, H.: The ALWIN MST radar technical design and performances, in: Proceedings of the 14th ESA Symposium on European Rocket and Balloon Programmes and Related Research, Potsdam, Germany (ESA SP-437), edited by: Kaldeich-Schürmann, B., pp. 179-184, 1999.

Lehmacher, G. and Lübken, F.-J.: Simultaneous observation of convective adjustment and turbulence generation in the mesosphere, Geophys. Res. Lett., 22, 2477-2480, doi:10.1029/95GL02351, 1995.

Lie-Svendsen, Ø., Blix, Т. A., Hoppe, U.-P., and Thrane, E. V.: Modelling the plasma response to small-scale particle perturbations in the mesopause region, J. Geophys. Res., 108(D8), 8442, doi:10.1029/2002JD002753, 2003.

Lübken, F.-J., Giebeler, J., Blix, T. J., Thrane, E., Singer, W., and Bremer, J.: In situ measurement of the Schmidt number within a PMSE layer, Geophys. Res. Lett., 21, 1651-1654, 1994.

Lübken, F.-J., Rapp, M., Blix, T., and Thrane, E.: Microphysical and turbulent measurements of the Schmidt number in the vicinity of polar mesosphere summer echoes, Geophys. Res. Lett., 25, 893-896, doi:10.1029/98GL50479, 1998.

Lübken, F.-J., Rapp, M., and Hoffmann, P.: Neutral air turbulence and temperatures in the vicinity of polar mesosphere summer echoes, J. Geophys. Res., 107(D15), 4273-4277, doi:10.1029/ 2001JD000\,915, 2002.

Lynch, K. A., Gelinas, L. J., Kelley, M. C., Collins, R. L., Widholm, M., Rau, D., MacDonald, E., Liu, Y., Ulwick, J., and Mace, P.: 
Multiple sounding rocket observations of charged dust in the polar winter mesosphere, J. Geophys. Res., 110(A3), A03302, doi: 10.1029/2004JA010502, 2005.

Marti, J. and Mauersberger, K.: A survey and new measurements of ice vapor pressure at temperatures between 170 and $250 \mathrm{~K}$, Geophys. Res. Lett., 20, 363-366, 1993.

Megner, L., Khaplanov, M., Baumgarten, G., Gumbel, J., Stegman, J., Strelnikov, B., and Robertson, S.: Large mesospheric ice particles at exceptionally high altitudes, Ann. Geophys., 27, 943951, 2009, http://www.ann-geophys.net/27/943/2009/.

Rapp, M. and Lübken, F.-J.: On the nature of PMSE: Electron diffusion in the vicinity of charged particles revisited, J. Geophys. Res., 108(D8), 8437, doi:10.1029/2002JD002857, 2003.

Rapp, M. and Lübken, F.-J.: Polar mesosphere summer echoes (PMSE): Review of observations and current understanding, Atmos. Chem. Phys., 4, 2601-2633, 2004, http://www.atmos-chem-phys.net/4/2601/2004/.

Rapp, M. and Strelnikova, I.: Measurements of meteor smoke particles during the ECOMA-2006 campaign: 1. particle detection by active photoionization, J. Atmos. Sol. Terr. Phys., 71, 477-485, doi:10.1016/j.jastp.2008.06.002, 2009.

Rapp, M. and Thomas, G. E.: Modeling the microphysics of mesospheric ice particles - Assessment of current capabilities and basic sensitivities, J. Atmos. Sol. Terr. Phys., 68, 715-744, 2006.

Rapp, M., Gumbel, J., and Lübken, F.-J.: Absolute density measurements in the middle atmosphere, Ann. Geophys., 19, 571580, 2001, http://www.ann-geophys.net/19/571/2001/.

Rapp, M., Lübken, F.-J., Müllemann, A., Thomas, G. E., and Jensen, E. J.: Small scale temperature variations in the vicinity of NLC: Experimental and model results, J. Geophys. Res., 107(D19), 4392, doi:10.1029/2001JD001241, 2002.

Rapp, M., Lübken, F.-J., and Blix, T. A.: Small scale density variations of electrons and charged particles in the vicinity of polar mesosphere summer echoes, Atmos. Chem. Phys., 3, 13991407, 2003, http://www.atmos-chem-phys.net/3/1399/2003/.

Rapp, M., Hedin, J., Strelnikova, I., Friedrich, M., Gumbel, J., and Lübken, F.-J.: Observations of positively charged nanoparticles in the nighttime polar mesosphere, Geophys. Res. Lett., 32, L23,821, doi:10.1029/2005GL024676, 2005.
Rapp, M., Strelnikova, I., Latteck, R., Hoffmann, P., Hoppe, U.P., Häggström, I., and Rietveld, M.: Polar Mesosphere Summer Echoes (PMSE) studied at Bragg wavelengths of $2.8 \mathrm{~m}, 67 \mathrm{~cm}$, and $16 \mathrm{~cm}$, J. Atmos. Sol. Terr. Phys., 70, 947-961, doi:10.1016/ j.jastp.2007.11.005, 2008.

Rapp, M., Strelnikova, I., Strelnikov, B., Latteck, R., Baumgarten, G., Li, Q., Megner, L., Gumbel, J., Friedrich, M., Hoppe, U.P., and Robertson, S.: First in situ measurement of the vertical distribution of ice volume in a mesospheric ice cloud during the ECOMA/MASS rocket-campaign, Ann. Geophys., 27, 755-766, 2009 , http://www.ann-geophys.net/27/755/2009/.

Robertson, S., Horányi, M., Knappmiller, S., et al.: Mass analysis of charged aerosol particles in NLC and PMSE during the ECOMA/MASS campaign, Ann. Geophys., 27, 1213-1232, 2009 , http://www.ann-geophys.net/27/1213/2009/.

Røyrvik, O. and Smith, L. G.: Comparison of mesospheric VHF radar echoes and rocket probe electron concentration measurements, J. Geophys. Res., 89, 9014-9022, 1984.

Seele, C. and Hartogh, P.: Water vapor of the polar middle atmosphere: Annual variation and summer mesosphere conditions as observed by ground-based microwave spectroscopy, Geophys. Res. Lett., 26, 1517-1520, doi:10.1029/1999GL900315, 1999.

Strelnikov, B., Rapp, M., and Lübken, F.-J.: A new technique for the analysis of neutral air density fluctuations measured in situ in the middle atmosphere, Geophys. Res. Lett., 30, 2052, doi: 10.1029/2003GL018271, 2003.

Strelnikov, B., Rapp, M., Zecha, M., Blix, T., Friedrich, M., and Yeoman, T.: Pmse and e-region plasma instability:in situ observations, J. Atmos. Sol. Terr. Phys., 71, 143-157, doi: 10.1016/j.jastp.2008.10.003, 2009.

Strelnikova, I., Rapp, M., Strelnikov, B., Baumgarten, G., Brattli, A., Svenes, K., Hoppe, U.-P., Friedrich, M., Gumbel, J., and Williams, B. P.: Measurements of meteor smoke particles during the ECOMA-2006 campaign: 2. results, J. Atmos. Sol. Terr. Phys., 71, 486-496, doi:10.1016/j.jastp.2008.07.011, 2009.

Tatarskii, V. I.: The effects of the turbulent atmosphere on wave propagation, Jerusalem: Israel Program for Scientific Translations, 1971. 